\title{
Preliminary Study of the Influence of Some Meteorological Parameters on the Concentration of CO in South Eastern Part of Nigeria
}

\author{
S. O. NGELE ${ }^{\mathrm{a}^{*}}$, A. N. EBOATU ${ }^{\mathrm{b}}$ and F. K. ONWU \\ ${ }^{a}$ Department of Industrial Chemistry, Ebonyi State University, P.M.B.053, \\ Abakaliki , Ebonyi State, Nigeria \\ ${ }^{\mathrm{b}}$ Department of Pure and Industrial Chemistry, Nnamdi Azikiwe University, Awka, Nigeria \\ sonngele@yahoo.com
}

Received 2 June 2012 / Accepted 25 June 2012

\begin{abstract}
This study monitored the ambient air levels of carbon monoxide, and selected meteorological parameters such as temperature, relative humidity and wind speed using portable digital on-site read out instrument in ten major urban centres in south eastern part of Nigeria. The monitoring was done twice a month for the $\mathrm{CO}$ and once a month for the meteorological parameters. The duration of the monitoring was four months in dry season and four months in the wet season. The results showed annual mean values of $0.896 \pm 0.882 \mathrm{ppmv}, 34.46 \pm 3.52{ }^{\circ} \mathrm{C}, 63.72 \pm 3.40 \%$ and $0.77 \pm 0.43 \mathrm{~ms}^{-1}$ for $\mathrm{CO}$, temperature, relative humidity and wind speed respectively. The correlation analysis revealed that among the meteorological parameters studied only wind speed is strongly correlated with CO. The regression result gave an adjusted $R$ - square value of 0.783 implying that the meteorological parameters studied jointly influence $78.3 \%$ variation in the level of $\mathrm{CO}$ in the south eastern Nigeria.
\end{abstract}

Keywords: MultiRae PGM 7840, Anemometer L 934853, Linear regression, South eastern Nigeria, Carbon monoxide, Meteorological parameters, Ambient air pollutant

\section{Introduction}

Air pollution is one of the current environmental challenges of the developed and developing economies of the world. While most of the developed countries are tackling the problem head long, the story is different in most developing countries where reliable data on air pollution is either scanty or non existent ${ }^{1,2}$.

$\mathrm{CO}$ is one of the toxic gaseous pollutants ${ }^{3}$ that is present in high concentration in the indoor and out door environment in the urban centres. The concentration of a pollutant in the ambient air of a particular place is dependent on many variables which include the proximity of pollution source, source strength, the atmospheric reactivity, the prevailing local meteorological parameters and topography. The concentration of gaseous pollutants and particulates in the ambient air is known to be affected by weather ${ }^{4,5}$. This has led to a growing body of research on assessing the impacts of a changing climate on regional air quality ${ }^{6}$. 
There are however certain aspects of air pollution - weather issues that are still difficult to understand. One of these is the issue of estimating the sensitivity of air pollutants to individual meteorological parameters. The difficulty stem among other reasons from the fact that meteorological parameters are by their nature linked resulting in strong interdependence. For instance, surface temperature is known to be linked with radiation ${ }^{7}$. Again, meteorological parameters can affect pollutants through direct physical mechanism or indirectly through influences on other meteorological parameters. For example while the production of ozone in the atmosphere by radiation is by direct physical mechanism, the link between high temperatures and low wind speed has indirect influence ${ }^{6}$.

More so, the amount and nature of these effects can present variations from one air shed to the next as well as across seasons ${ }^{8,9}$. Thus inquiry as to the true nature of the meteorological parameters- pollutant relationship requires multiple approaches. One such approach addressing the effects of meteorological parameters on air pollution is statistical modelling. It is suited in quantifying and highlighting the nature of pollutant response to individual meteorological parameters as they fit to the patterns derived from the obtained field data ${ }^{10-12}$. With increasing urban population due to rural - urban drift in major city centres in Nigeria ${ }^{13}$, there are consequential added pressures on air pollution emissions with resultant environmental degradation and negative human health effects.

The objective of this work is to monitor $\mathrm{CO}$, one of the criteria pollutants and meteorological parameters such as relative humidity, wind speed, temperature in the major city centres in south eastern Nigeria and predict the individual and aggregate influence of the meteorological parameters on the $\mathrm{CO}$ concentration using multiple regression analysis as a tool.

\section{Experimental}

The study area covered two major urban centres in each of the five states: Abia, Anambra, Ebonyi, Enugu and Imo in the south-eastern part of Nigeria. South eastern Nigeria is known for trade and commerce and has a tropical climate. It has a population of 16, 382, 029 constituting $11.20 \%$ of the Nigerian population according to 2006 population census Figure ${ }^{14}$. The activities in the study areas that may likely impact negatively on the air environment include coal exploitation, cement production, network of roads with high vehicular volume, quarrying and mining of solid mineral and precious stones.

\section{Site selection}

The urban centres were not properly demarcated into industrial, commercial and residential areas hence the allocation of the sampling sites in each city were based on spreading the sites evenly so as to cover major anthropogenic activities in the city.

\section{$\mathrm{CO}$ and meteorological parameter monitoring}

The experiment was designed to monitor $\mathrm{CO}$ concentration, temperature, relative humidity and wind speed levels in the designated sites in all the selected ten urban centre (Aba, Umuahia, Nnewi, Onistsha, Abakaliki, Afikpo, Enugu, Nsukka, Orlu and Owerri) in the south eastern part of Nigeria. The CO monitoring was done once fortnightly for four months in the dry season-December, 2007, January, -March 2008 and four months in the wet season June - September 2008. The CO monitoring was carried out using on-site digital instrument, Multirea programmable gas monitor model PGM 7840 at a height of $1.5 \mathrm{~m}$ above ground level the height of human respiration of air pollutants ${ }^{15}$. The meteorological parameters were also monitored at the same height using portable digital hand held instrument, Anenometer Extech model L. 934853. This instrument gives direct on site reading 
of each of the meteorological parameters (temperature, relative humidity and wind speed) by selecting and switching on the appropriate parameter on the instrument. The values obtained from each site within the eight months monitoring was averaged to obtain the site average and from the site averages, the urban centre average was calculated for each of the parameters.

\section{Linear regression modelling}

Simple linear regression models with the generated linear coefficients for covariants were used $^{16,12}$. This approach even though may not be too effective in the incorporation of the complex non-linearity nature of some pollution research but is adopted here for ease of interpretation. This linear regression model in the context of variation in the concentration of carbon monoxide as a function of average changes in temperature, relative humidity and wind speed is usually expressed in equation form.

$\mathrm{CO}=\mathrm{f}$ (ITemperature, relative humidity, wind speed). This can be modelled using the equation below: $\mathrm{CO}=\beta \mathrm{O}+\beta_{1} \mathrm{Ti},+\beta_{2} \mathrm{RHi}+\beta_{3} \mathrm{WSi}+\alpha \mathrm{i}$.

Where, $\mathrm{CO}$ represents average variation in carbon monoxide concentration. Ti stands for average temperature level for each of the sampled cities in south-eastern part of Nigeria. RHi is the average relative humidity level for each of the sampled cities in south-eastern part of Nigeria. WSi stands for the average wind speed for each of the sampled cities in the south-eastern part of Nigeria. $\alpha \mathrm{i}$ is the error term. $\beta \mathrm{o}, \beta_{1}, \beta_{2}$ and $\beta_{3}$ are regression coefficients of interest.

\section{Characterization of the meteorological effect}

The goodness of the model above in revealing the relations between the studied meteorological variables and the CO pollutant was measured using the $R$-statistics and more accurately using the adjusted $R$ - statistics which eliminated the covariant due to other parameters not of interest.

\section{Results and Discussion}

$\mathrm{CO}$ is one of the criteria air pollutants regulated and monitored under the US National Ambient Air Quality Standard ${ }^{17,7}$. Studies have linked ambient air CO concentration to volcanic eruption, mining activities, solid waste decay and incineration but more importantly to vehicular emissions from fossil fuel combustion ${ }^{18-22}$.

In this study, the maximum and minimum annual CO levels were $3.161 \pm 1.45$ and $0.26 \pm 0.10$ ppmv respectively recorded in Enugu and Afikpo urban centres (Table 1-5). This may be attributed to the levels of $\mathrm{CO}$ emission activities in these urban centres. Also the maximum and minimum annual levels of temperature, relative humidity and wind speed were $39.73 \pm 0.37,28.65 \pm 0.30{ }^{\circ} \mathrm{C}, 70.62 \pm 0.42,61.33 \pm 1.84 \%$ and $1.98 \pm 0.22$, $0.52 \pm 0.43 \mathrm{~m} / \mathrm{s}$ respectively (Table 5). From Table 5, Enugu has the highest mean level of $\mathrm{CO}$, temperature and wind speed. The relatively higher levels of temperature and wind speed may be connected to the topography (that is higher attitude) of the city relative to other cities in this study. The higher level of $\mathrm{CO}$ may be due to vast network of roads with the attendant vehicular exhaust emission, coal mining activities, organic solid waste decomposition and combustion ${ }^{18,21}$. Table 6 shows the correlation coefficients and descriptive statistics between $\mathrm{CO}$ and selected meteorological parameters. 
The results indicated that both temperature and wind speed have positive correlation with $\mathrm{CO}$ although it is only the effect of wind speed that is strongly significant $[p<0.01]$. The relationship between $\mathrm{CO}$ and relative humidity is negative and not significant (Table 6). This implies that wind speed among the three meteorological parameters studied has much influence on the variation of the $\mathrm{CO}$ in the south-eastern part of Nigeria giving as high as $90.8 \%$ correlation coefficient.

Table 1. Annual range/ mean concentrations of $\mathrm{CO}$ in ten urban centres in South East Nigeria (ppmv)

\begin{tabular}{cccc}
\hline Urban centre & Max & Min & Mean concentration \\
\hline Aba & 2.8 & 0.1 & $0.66 \pm 0.18$ \\
Umuahia & 4.0 & 0.1 & $0.79 \pm 0.59$ \\
Nnewi & 1.6 & 0.1 & $0.79 \pm 0.17$ \\
Onitsha & 5.5 & 0.1 & $0.18 \pm 0.08$ \\
Abakaliki & 6.0 & 0.1 & $1.57 \pm 0.61$ \\
Afikpo & 1.0 & 0.1 & $0.26 \pm 0.10$ \\
Enugu & 10.0 & 0.1 & $3,16 \pm 1.45$ \\
Nsukka & 1.2 & 0.1 & $0.48 \pm 0.42$ \\
Orlu & 2.0 & 0.1 & $0.59 \pm 0.20$ \\
Owerri & 2.0 & 0.2 & $0.78 \pm 0.20$ \\
\hline
\end{tabular}

Table 2. Annual range and mean levels of temperature $\left({ }^{\circ} \mathrm{C}\right)$

\begin{tabular}{cccc}
\hline Urban Centre & Max & Min & Mean \\
\hline Aba & 33.2 & 25.6 & $31.25 \pm 0.73$ \\
Umuahia & 33.5 & 29.0 & $28.65+0.30$ \\
Nnewi & 39.4 & 35.1 & $38.73 \pm 0.14$ \\
Onitsha & 36.8 & 34.0 & $35.52 \pm 0.45$ \\
Abakaliki & 38.0 & 34.2 & $35.55 \pm 0.42$ \\
Afikpo & 36.1 & 32.4 & $35.32 \pm 0.58$ \\
Enugu & 40.5 & 33.0 & $39.73 \pm 0.37$ \\
Nsukka & 37.1 & 28.6 & $35.45 \pm 0.28$ \\
Orlu & 36.6 & 29.0 & $34.17 \pm 0.28$ \\
Owerri & 32.6 & 28.1 & $30.26 \pm 0.49$ \\
\hline
\end{tabular}

Table 3. Annual range and mean levels of wind speed $(\mathrm{m} / \mathrm{s})$

\begin{tabular}{cccc}
\hline Urban centre & Max & Min & Mean \\
\hline Aba & 1.2 & 0.2 & $0.63 \pm 0.24$ \\
Umuahia & 1.2 & 0.2 & $0.52 \pm 0.43$ \\
Nnewi & 0.8 & 0.3 & $0.56 \pm 0.33$ \\
Onitsha & 1.3 & 0.3 & $0.67 \pm 0.02$ \\
Abakaliki & 1.6 & 0.1 & $0.79 \pm 0.12$ \\
Afikpo & 1.2 & 0.2 & $0.70 \pm 0.10$ \\
Enugu & 5.5 & 0.8 & $1.98 \pm 0.22$ \\
Nsukka & 1.2 & 0.5 & $0.72 \pm 0.63$ \\
Orlu & 0.8 & 0.1 & $0.59 \pm 0.21$ \\
Owerri & 1.2 & 0.2 & $0.58 \pm 0.30$ \\
\hline
\end{tabular}


Table 4. Annual range and mean levels of relative humidity in urban centres in southeastern Nigeria (\%)

\begin{tabular}{cccc}
\hline Urban centre & Max & Min & Mean \\
\hline Aba & 74 & 45 & $70.62 \pm 0.42$ \\
Umuahia & 73 & 48 & $64.89 \pm 0.34$ \\
Nnewi & 82 & 43 & $61.33 \pm 1.84$ \\
Onitsha & 84 & 48 & $62.19 \pm 0.54$ \\
Abakaliki & 82 & 44 & $65.28 \pm 1.27$ \\
Afikpo & 88 & 41 & $61.81 \pm 1.68$ \\
Enugu & 79 & 40 & $61.47 \pm 0.67$ \\
Nsukka & 70 & 34 & $62.35 \pm 0.25$ \\
Orlu & 68 & 48 & $62.27 \pm 0.13$ \\
Owerri & 70 & 46 & $63.00 \pm 0.32$ \\
\hline
\end{tabular}

Table 5. Annual average levels of $\mathrm{CO}$ and selected metrological parameters in some urban centres in the south eastern part of Nigeria

\begin{tabular}{ccccccccc}
\hline & \multicolumn{2}{c}{ CO, ppmv } & \multicolumn{2}{c}{$\mathrm{T},{ }^{0} \mathrm{C}$} & \multicolumn{2}{c}{ RH, \% } & \multicolumn{2}{c}{ WS, ms ${ }^{-1}$} \\
Urban Centre & Mean & S/Dev & Mean & S/Dev & Mean & S/Dev & Mean & S/Dev \\
\hline Aba & 0.66 & 0.18 & 31.25 & 0.73 & 70.62 & 0.42 & 0.63 & 0.10 \\
Umuahia & 0.79 & 0.59 & 28.65 & 0.30 & 64.89 & 0.34 & 0.52 & 0.43 \\
Nnewi & 0.49 & 0.17 & 38.73 & 0.14 & 61.33 & 1.84 & 0.56 & 0.33 \\
Onitsha & 0.18 & 0.08 & 35.52 & 0.45 & 62.19 & 0.54 & 0.67 & 0.02 \\
Abakaliki & 1.57 & 0.61 & 35.55 & 0.42 & 65.28 & 1.27 & 0.79 & 0.12 \\
Afikpo & 0.26 & 0.10 & 35.32 & 0.58 & 61.81 & 1.68 & 0.70 & 0.10 \\
Enugu & 3.16 & 1.45 & 39.73 & 0.37 & 61.47 & 0.67 & 1.98 & 0.22 \\
Nsukka & 0.48 & 0.42 & 35.45 & 0.28 & 62.35 & 0.25 & 0.72 & 0.63 \\
Orlu & 0.59 & 0.20 & 34.17 & 0.28 & 62.27 & 0.13 & 0.59 & 0.21 \\
Owerri & 0.78 & 0.20 & 30.26 & 0.49 & 62.00 & 0.32 & 0.58 & 0.50 \\
\hline
\end{tabular}

Table 6. Correlation coefficients and the descriptive statistics on the $\mathrm{CO}$ and selected metrological parameters in the south eastern part of Nigeria

\begin{tabular}{|c|c|c|c|c|}
\hline & $\mathrm{CO}$ & Temp, $\mathrm{T}^{\circ} \mathrm{C}$ & $\begin{array}{l}\text { Rel. Humidity } \\
\text { (RH) }\end{array}$ & $\begin{array}{c}\text { Wind } \\
\text { Speed (WS) }\end{array}$ \\
\hline $\mathrm{CO}$ & 1.000 & & & \\
\hline Temp (T) & $\begin{array}{c}0.399 \\
(0.254)\end{array}$ & 1.000 & & \\
\hline $\begin{array}{l}\text { Rel. Humidity } \\
\text { (RH) }\end{array}$ & $\begin{array}{l}-0.070 \\
(0.848)\end{array}$ & $\begin{array}{l}-0.527 \\
(0.118)\end{array}$ & 1.000 & \\
\hline Wind Speed (WS) & $\begin{array}{l}0.908^{* *} \\
(0.000)\end{array}$ & $\begin{array}{l}0.587^{*} \\
(0.074)\end{array}$ & $\begin{array}{l}-0.225 \\
(0.532)\end{array}$ & 1.000 \\
\hline Mean & 0.896 & 34.463 & 63.721 & 0.774 \\
\hline S/Dev. & 0.882 & 3.525 & 3.404 & 0.432 \\
\hline Minimum & 0.180 & 28.650 & 61.330 & 0.520 \\
\hline Maximum & 3.160 & 39.730 & 72.620 & 1.980 \\
\hline
\end{tabular}

**, "Imply significant coefficient at 1\%, and $10 \%$ levels, respectively 
The F-value at 11.85 (Table 7) is significant $(\mathrm{P}<0.01)$ implying that the overall model is very efficient in explaining the relationship between $\mathrm{CO}$ and each of the selected meteorological parameters. The results also indicated that temperature $(\mathrm{T})$, relative humidity $(\mathrm{RH})$ and wind speed (WS) jointly account for as high as $78.3 \%$ of the variation in the concentration of $\mathrm{CO}$ in the South Eastern part of Nigeria. On the individual effect, the results show that both relative humidity and wind speed affect variation in the concentration of $\mathrm{CO}$, although it is only the effect of wind speed that is strongly and positively significant (Table 6). The relationship between temperature and $\mathrm{CO}$ is positive but not significant (Table 6). Therefore among the three meteorological parameters, wind speed appears to be the most important factor in explaining variations in the concentration of carbon monoxide in the South Eastern part of Nigeria.

Table 7. Regression results on the relationship between $\mathrm{CO}$ and each of the selected metrological parameters

\begin{tabular}{cccc}
\hline & Coefficient & $t$-Statistics & Prob. $>|\mathrm{t}|$ \\
\hline Temp (T) & -0.040 & -0.720 & 0.499 \\
Rel. Humidity (RH) & 0.020 & 0.410 & 0.697 \\
Wind Speed (WS) & $2.082^{*}$ & 5.270 & 0.002 \\
Constant & -0.583 & -0.140 & 0.895 \\
$R$-Square & 0.856 & & \\
Adjusted $R$-Square & 0.783 & & \\
$F$-Value & 11.85 & & \\
Prob>F & 0.006 &
\end{tabular}

\section{Conclusion}

$\mathrm{CO}$ is one of the naturally and anthropogenically generated gaseous pollutants that is particularly in high concentration in the environment. This study has obtained the annual mean level of the pollutant $(\mathrm{CO})$ as well as that of three meteorological parameters (temperature, relative humidity and wind speed) in ten major urban centres in south eastern part of Nigeria. The work afforded a linear empirical model by taking $\mathrm{CO}$ as the dependent variable and the three meteorological parameters as the independent variables. The research showed that among three meteorological parameters postulated as influencing the CO levels in the study area, wind speed is the most significant.

\section{References}

1. Derek G S and Luke P N, Environ Int., 2002, 28, 375-382.

2. Akeredolu F P, Atmos Environ., 1989, 23(4), 7-10.

3. Raub J A, Mathieunolf M, Hampson N B and Thom S R, Toxicology, 2000, 145, 1-14

4. $\quad$ Beaver S and Palazoglu A, Atmosp Environ., 2009, 43(10), 1779-1788.

5. Elminir H K, Science of the Total Environment, 2005, 350(1-3), 225 -237.

6. Jacob D J and Winner D A, Atmospheric Environment, 2009, 43(1), 51 -63.

7. Robert Stewart, Earth Radiation Balance and Oceanic Heat Fluxes, Oceanography in the $21^{\text {st }}$ Century- An online Textbook @ http://oceanworld.tamu.edu/resources/oceanography-book/radiationbalance.htm

8. USEPA, Assessment of impacts of global change on regional U. S Air Quality: A synthesis of climate change impacts on Ground level ozone U. S. E. P. A Washington, DC, 2009. 
9. Dawson J P, Adams P J and Pandis S N, Atmosp Environ., 2007, 41(7), 1494 -1511.

10. Schlink U and Herberth O, Environ Modelling Software, 2006, 21(4), 547 - 558.

11. Hastie T J and Tibshirani R J, Generalized Additive models. London Chapman and Hall, 1990.

12. Harvel A F E, Regression Modelling strategies: with Applications to linear models, logistic Regression, Springer, 2001.

13. Obienusi E A, Nigrian Urban Population Growth in: Urban Environmental Problems in Nigeria Nnodu, V C, Okoye C O and Onwuka S U (Eds.), Rex Charles and Patrick Publications, Enugu Nig., 2008, Pp. 55-63.

14. National Population census. NPC 2006 Nigerian population and Demographic data Report, 2006.

15. USEPA, Air Quality Criteria for Particulate Matter, (Executive Summary) Fourth External Review Draft, Vol 1, 2003.

16. Garger E K, Hoffman F O and Thiessen K M, J Environ Radioactivity, 1999, 42, 157 175.

17. Commission of the European communities (2005) Proposal for Directive of the European parliament and of the council on ambient air quality and cleaner air for Europe presented by the commission on 21- 9-2005 in Brussels.

18. Nonroad Engine and Vehicle Emission Study Report (EPA-21A-2001 or EPA460/ 391-02, November 1991

19. Millennium Ecosystem assessment report. UN consults on Air pollution plan. $J$ Environment, 2005, 7, 405-410.

20. UNEP and WHO, Air pollution in the World's Mega cities, Environment, 36 March 1994.

21. Qadir N F, Air quality in urban Area in Pakistan vs Transport planning, Report of study sponsored by Asian development Bank, 2005.

22. Vaitiekunas P and Banaityle R, J Environ Eng Landsc Manag., 2007, 15(1), 39-46. 